\title{
MOTIVATIONAL LEAN GAME TO SUPPORT DECISION BETWEEN PUSH AND PULL PRODUCTION STRATEGY
}

\author{
Herakovic, N.*; Metlikovic, P., ${ }^{* * *} \&$ Debevec, M.* \\ * Laboratory for Handling, Assembly and Pneumatics, Faculty of Mechanical Engineering, University \\ of Ljubljana, Askerceva 6, SI-1000 Ljubljana, Slovenia, EU \\ ${ }^{* *}$ PTICA - Institute of education, research and consulting, Jesetova 25, SI-4000 Kranj, Slovenia, EU \\ E-Mail: niko.herakovic@fs.uni-lj.si, peter.metlikovic@siol.net, miha.debevec@fs.uni-lj.si
}

\begin{abstract}
In this paper, we present and propose the interactive push-pull lean game with a specific approach for training/testing of production processes. With our approach of combining the psychologically effective physical lean game and the simulation lean game for deeper analyses of the production process, we can successfully overcome the communication and motivation problems of production and management workers when new production strategies are being introduced into the company to raise the competitiveness. The game only takes two hours and it has been proven to be effective with leadership teams and shop floor workers alike in more than 50 real-case production environments. The game is played in two parts where each part is in sharp contrast to the other with respect to results. Once the participants of the game see the effects of both production strategies, they become extremely engaged and motivated, and it becomes much easier to manage organizational improvements. In the third chapter of the paper, we present the Virtual factory computer models of the game dynamic, showing the same results as obtained with groups. The two simulation models serve to test and verify the interactive game. The paper ends with the discussion and conclusions.

(Received in December 2013, accepted in May 2014. This paper was with the authors 2 months for 1 revision.)
\end{abstract}

Key Words: Lean Game, Push, Pull, Production Optimization, Virtual Factory, Production Simulation

\section{INTRODUCTION}

As discussions among researchers, analysts and industry experts about the $»$ Factory of the Future « are becoming more and more frequent [1], many manufacturers as well as education and trainee experts begin to refocus. For many of them the goal is to effectively manage the inevitable constraints and the enablement of the demand-driven systems to drive on-time production. A modern manufacturing practice is therefore very often based on different production theories like Just in Time, Lean production, Kanban and Pull systems, based on the Toyota production system (TPS) etc., as well as on the supply chain and the overall equipment efficiency (OEE) optimization [2-7].

The lean system has even become a reference model for optimizing the production and general performance of larger companies as well as SMEs [8-10]. Therefore, some research works focus on the simulation of production processes as well as on the material flow and batch quantity optimization [11-13]. Any overproduction, as well as any excess stock is considered to be a source of waste [14-17]; producing only what is really needed by the customer is one of the major principles of lean manufacturing. One way to think about waste is in terms of the push and pull systems. Lean production is based on the pull system and reduces excess stocks of finished products as well as enables the decrease of immobilization costs related to over-storage. A pull system only produces what a customer needs or has asked for. A push system, like much of traditional manufacturing, produces as much product as the company wants to produce and then gets it out to the customer. Usually, the result is large inventories. 
Lean philosophy can certainly help companies to reach the desired goal, but the change does not happen overnight. It demands time, and first of all, it demands determination, dedication and knowledge from the company's leadership and all the employees. Nowadays, many companies which want to introduce advanced and effective production principles suffer from the lack of human resources or, as it very commonly happens, they do not have enough appropriate knowledge to accept the challenge.

One of the crucial parts of the production process is industrial assembly which is influenced directly by the demand for the finished products. One of its main objectives is to minimize product shortages as well as excessive inventory [18]. In many companies, the assembly process is driven by the "push" system, which is based on the anticipated demand. In this case, the products are completed and sent to the next work station, or in the case of the final work station, they are pushed to the finished goods inventory. In the alternative "pull" system, the movement of work is based on the requirements of the following workstation. Each subsequent workstation pulls (demands) output from the previous workstation as needed. The next workstation determines how much output is requested and when. The output from the final workstation is pulled by the customer demand or the master production schedule. The pull system ensures that the right amount of products is produced at the right time, and aims for a continuous improvement of the assembly organization in terms of productivity, quality and flexibility. For the ideal pull system, the inventory at each stage is only one unit, but this cannot be implemented in a real manufacturing environment for several reasons, such as variation in processing times, imbalance of workloads among stages, unavoidable work station breakdown etc. Both, the push and the pull systems are tools used in social interactions which provide movement towards interaction and provoke response and action within it.

In an effort to improve the performance, production companies, especially their executives and managers, waste inordinate amounts of time and money during manufacturing because of organizational struggles between the push system and pull system. Many authors $[8,19-22]$ also discuss both strategies and develop support tools to clarify their suitability for the practical use and to help production companies in their decisions about introducing the push-pull system.

Because the decision is not easy, the understanding of both strategies is not adequate, and many organizations have not been successful in introducing new task and managerial methods into the workplace, considerable attention has been directed toward developing a more complete understanding of the push-pull systems. While pull-based systems are more and more popular, they require a shift in philosophy as well as in education and trainee systems for the management and for the employees in all levels of a production company. This brings new challenges to the social, political, and educational systems which are largely designed to support "push" economies.

Therefore, a fundamental need for the success of the introduction of a new organizational strategy into the production process or for the change of the existing one is obtaining support and agreement from all individuals involved in the achievement of organizational goals. It will require involving and informing all the groups who have an interest in the production process. Such an approach can reduce the amount of time and efforts involved in the implementing of the push or pull strategy enormously and can minimize the likelihood of the appearance of implementation problems. Support and agreement should be obtained from all the different stakeholders [6].

For this purpose, there is a huge need for the appropriate methodology or tool which would serve as a motivational approach in the introduction of the new optimization and organizational strategies into the production companies [23-31], including energy efficient systems [32-34]. 
In this paper, we therefore present and propose a specially developed motivational interactive lean game, which is particularly suitable for the use in educational programs at universities or in trainee programs at the workshops for the industry. The proposed lean game is simple to use and play so that every stakeholder of the company or of the educational program can take part in it and can understand its results clearly. Therefore, the game is very effective, and it deals with the push-pull production systems in the assembly process. It compares both production strategies to address the benefits and weaknesses of both systems. For a better evaluation of the effects of attributes changing in the assembly system, the lean game is also supported with a simulation approach using the Virtual Factory. This represents an effective tool for making the comparisons between different scenarios in the production system, also in a larger scale, by considering different attributes of the production, such as the change of the manufacturing system, the variation of demand, the number of buffer storages etc.

\section{MOTIVATIONAL LEAN GAME}

Apart from the technological point of view, production companies are also socio-technical systems where the social part is often neglected. Trying to manage change in a company without involving, engaging, motivating and informing everybody is a sure path to failure. Even well prepared and clearly delivered PowerPoint presentations of trainee experts during the lean workshops usually do not deliver a desirable result. In such cases, this Chinese proverb holds true: "Tell me and I'll forget; show me and I may remember; involve me and I'll understand."

Therefore, one of the best ways to engage people is through workshop games which strongly convey the message and provide a personal experience. In this article, we present this kind of a game. In the last four years, it has been played approximately 50 times, in different companies and organizations, in different workshops, with directors and with shop floor workers, in schools, at universities and in government. The game consists of two parts - the first is a lean game with the push strategy, and the second is a lean game with the pull strategy. Altogether with the preparation and explanation, the whole game takes 2 hours. Each part of the game lasts only 10 minutes. In all cases, the first part of the game resulted in disappointing results for the game participants/players, while the second part of the game delivered better results than expected.

The game addresses the most pressing need of any organization: how to provide a more proactive, better service with a shorter lead time while at the same time reducing cost.

\subsection{Push strategy - the first lean game}

The lean game consists of the assembly line of circuit boards. A5 size circuit boards (Fig. 1) are printed on yellow and green papers. Different functions of the circuit boards are represented by blue square stickers, white round stickers, paperclips, holes and lines which represent conduits connecting different parts together, while white-coloured circles represent soldered joints. In the first game (Fig. 1), a customer orders 20 pieces of paper circuit boards: 5 green pieces and 15 yellow pieces.

The first game requires 9 departments/stages. In the first department, an A4 sheet of paper is cut in half. In the second department, the blue squares are cut. In the third, holes are punched, in the fourth, the white colour (soldered joints) is applied, in the next department, stickers are attached, and in the sixth, staples are pressed and lines are drawn. Quality control and repair shop follow. To run this first part, 9 volunteers are needed, with the last one 
"driving the forklift", transporting 3 pieces at a time. If available, another 9 people measure what percentage of the 10 minutes was spent waiting, and what percentage working.

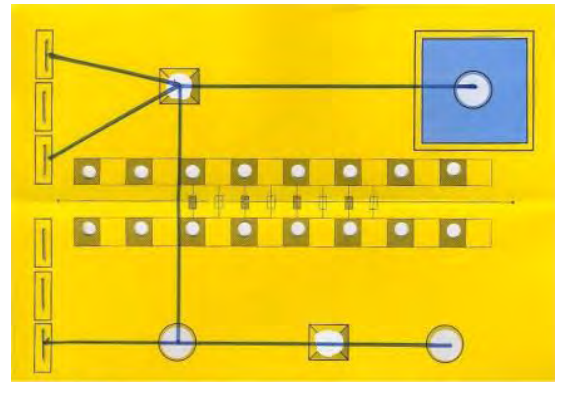

Process Parameters:

- push strategy

- 9 workers

- work cost: $1 € / \mathrm{sec}$

- material cost: $150 € /$ piece

- production cycle: $20 \mathrm{pcs} / \mathrm{shift}$

- work cost: $210 € /$ piece

- target cost: $360 €$

CUSTOMER order:

$600 \mathrm{sec}(10 \mathrm{~min})$

20 pcs: 5 green, 15 yellow
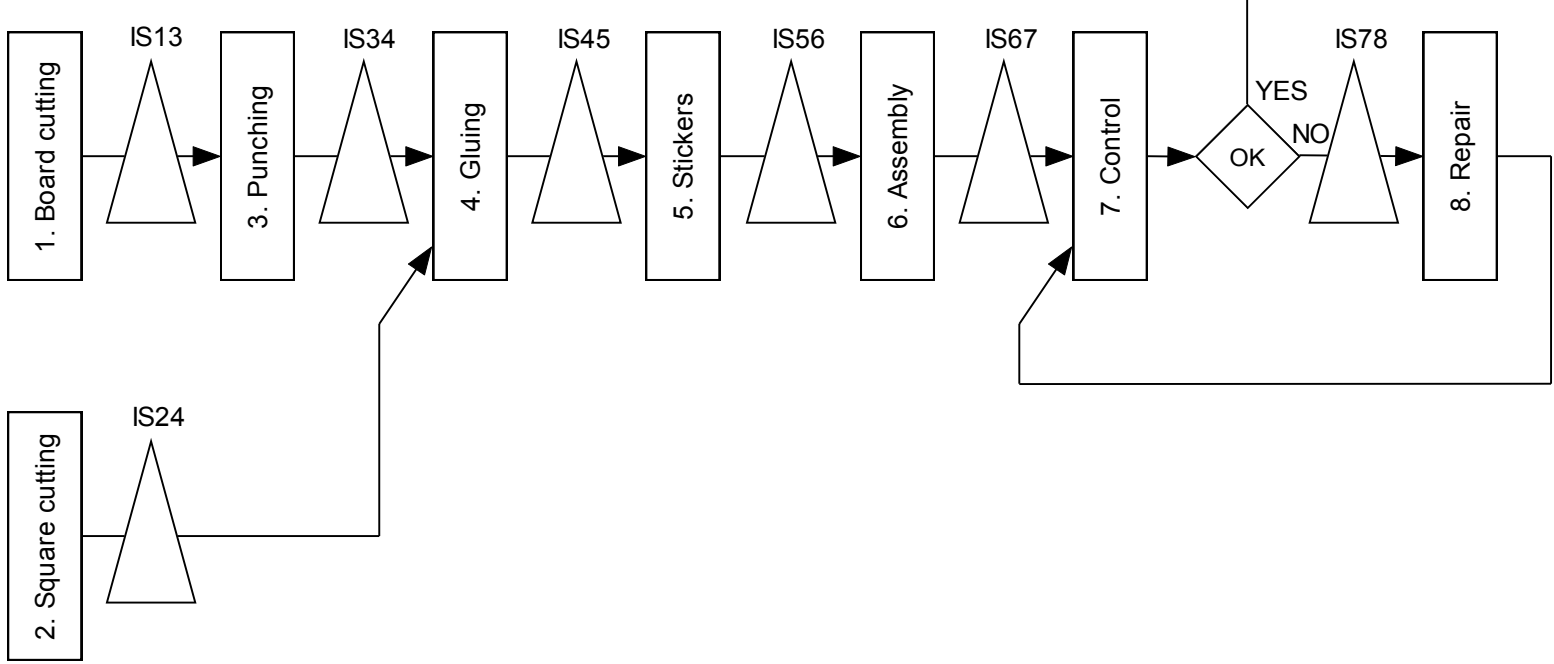

9. Transport between working stations by forklift

ISi - Intermediate Storage

material flow

Figure 1: Layout of the first lean game - push strategy, product (paper "circuit board"), customer order and manufacturing process.

Different quality criteria are defined, such as that a sticker must not go over the line, etc., which guarantee the quality of the product demanded by the buyer. All tasks can be easily trained in a few minutes in order to meet the quality criteria.

This kind of a manufacturing process is not atypical. For example, in companies with production technologies, such as cutting, machining, painting, testing, etc., we can find the same technologies grouped into departments, products traveling in batches through many stages etc. The production process can involve more companies and technologies, such as chroming outside. The same is true of service organizations, or the government. There are also many examples of having sales, purchasing, scheduling, controlling, R\&D, manufacturing, and finances on different locations, as well as having many suppliers and partners with long and unreliable response times. Long transportation paths and long response times, communication issues, quality problems, even forgetting what exactly the customer wanted in the first place is not uncommon in practice. All these issues are addressed by the lean game.

The results of the first lean game with the push strategy are repeatedly disappointing - a $10 \%$ margin is planned, while approximately a $500 \%$ loss results, with a lot of material consumed and only a few products delivered, typically with quality issues. 
In discussion, the participants and players of the game identify some of the issues, while suggestions are very different: they often include buying more forklifts, better machinery, employing more people. The suggestions are not much different than in everyday business life. The suggested solutions are to spend more resources, without going to the root causes of the poor process itself.

\subsection{Pull strategy - the second lean game}

The second lean game consists of the assembly line of the same circuit boards with the same characteristics as presented in Fig. 1 for the first lean game. Because of the disappointing results of the first lean game with the push strategy, the participants are informed before the beginning of the second lean game that if we had enough time in the workshop or in the education process we would discuss the problems and implementing solutions in detail and improve the assembly process little by little, until better results would follow.

In order to show the contrast between the results of the second game with the pull strategy and the results of the first game with the push strategy, we start the second lean game after only a short pause after the first game with a new process set up, as show in Fig. 2.
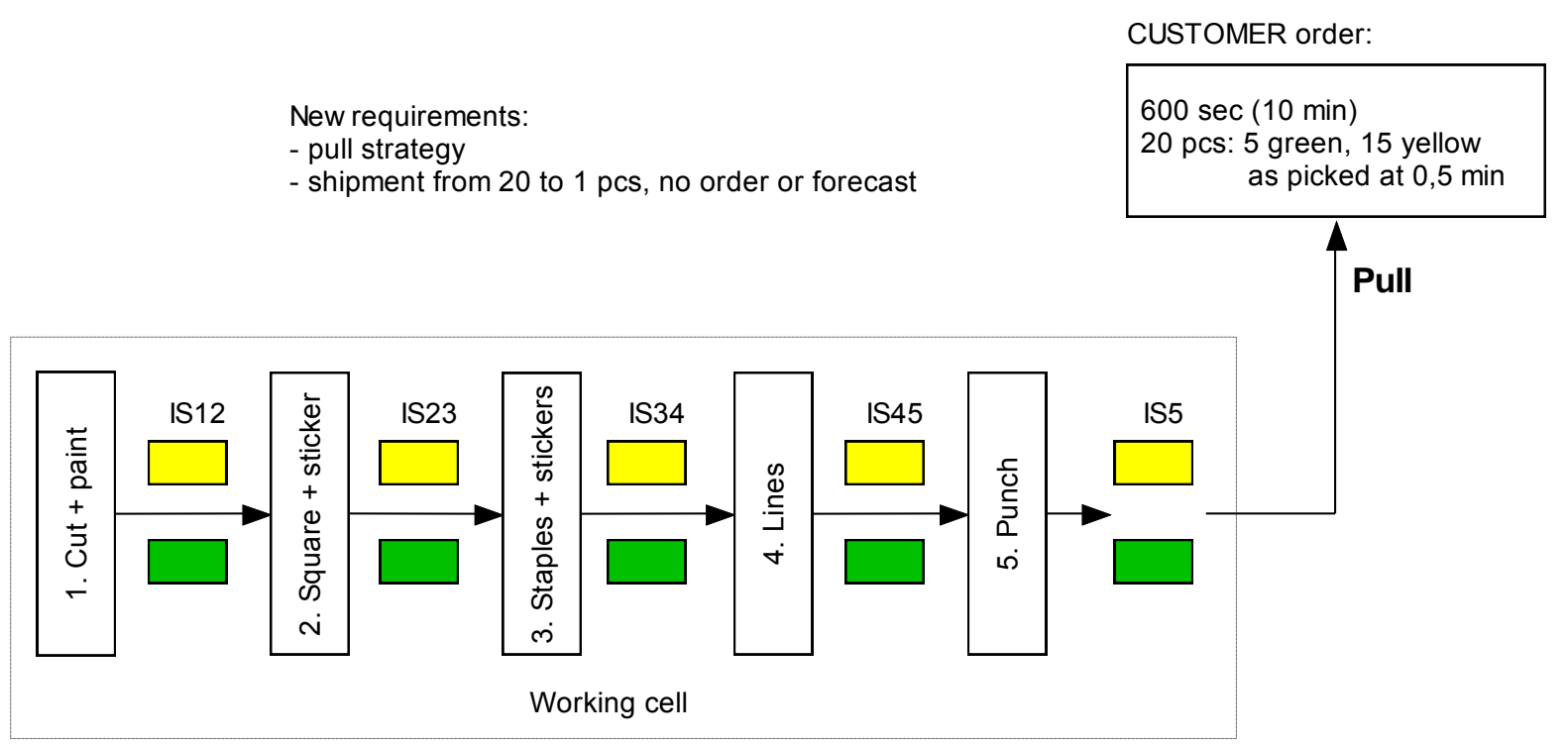

ISi - Intermediate Storage

$\longrightarrow$ material flow

Figure 2: Layout of the second lean game - pull strategy and customer order.

Instead of 9 stages of the game/assembly of the circuit boards, only 5 are needed in the second lean game. All the stages of the assembly process are placed in a U-cell, or along one long table in the workshop. For a better comparison of the results of the first and the second lean game, in the second game, 2 product codes are required: 1 yellow and 1green circuit board. But to make things complicated, the customer insists on not giving any order anymore, instead he pulls products every 30 seconds from the final warehouse.

Participants sit next to each other. Another 5 participants measure the waiting vs. working time. For training, the customer (game moderator) pulls one of the products from the final warehouse. Participants identify the empty space in the warehouse. Stage 5 takes on a board from the limited work in process on the left, performs punching and fills the warehouse. Stage 4 identifies the part on the right being pulled away, draws lines and replaces the product. In this way, the boards are being pulled through the process. 
The participants notice how effortlessly the new process works. It is also easy to ensure quality work by doing it right the first time and informing the previous stage in case of any issues. They sometimes look around astonished when realizing that work is not necessarily stressful and hectic. There is even time to chat or discuss improvements. The 10 minutes of the game pass easily and many products are made.

\subsection{KPIs of the push and pull strategies}

Immediately after the second lean game, the results are collected in an Excel spreadsheet (Table I) and visualized on a projector.

Table I: Key performance indicators of the first and the second games.

\begin{tabular}{|l|r|r|r|}
\hline & Target & Game 1 & Final Game \\
\hline Planned pcs & 20 & 2 & 18 \\
\hline Pcs per employee & 2,9 & 0,2 & 3,6 \\
\hline Time efficiency & $80 \%$ & $40 \%$ & $71 \%$ \\
\hline Takt (sec/pcs) & 30 & 300 & 33 \\
\hline Quality & $100 \%$ & $50 \%$ & $100 \%$ \\
\hline Accepted pcs & 20 & 1 & 18 \\
\hline Shifts needed & 1 & 20,0 & 1,1 \\
\hline Cost of work & & $5.400 €$ & $3.000 €$ \\
\hline Cost of quality & & $630 €$ & $240 €$ \\
\hline WIP and final stock & & $8.700 €$ & $780 €$ \\
\hline Cost per accepted pcs & $360 €$ & $6.330 €$ & $330 €$ \\
\hline Profit (selling price $=400 €)$ & $40 €$ & $-5.930 €$ & $70 €$ \\
\hline Profit (\%) & $10 \%$ & $-1483 \%$ & $18 \%$ \\
\hline
\end{tabular}

Participants notice that in the second game there is less effort needed, but they are typically surprised that the results are so much better. In spite of the more difficult requirements of the customer where the response time requirement went from 10 minutes to 30 seconds, the costs are way bellow technological calculations.

At this point, discussion is critical. The participants have experienced something new, they are excited and curious, and are looking for an explanation. We did not change customers, or suppliers, or workers, or technology. We merely moved and sat in a different order. We changed a disastrous process into a functional one.

Let us have a look at what the characteristics of the new functional process are:

1) it is designed around customer needs, allowing the customer to pull what is needed when it is needed,

2) the products (or value, in the case of services) are delivered in flow, being pulled from a connected process,

3) the quality is not eliminated, but is merely included in every work operation as a combination of skill, culture and attitude of everybody involved. Mistakes cannot remain hidden,

4) the work in process is limited to two pieces, minimizing the tied capital and ensuring maximum flexibility,

5) the load is balanced, everybody can work slowly without stressing or cutting corners,

6) individual workers are trained in more technologies, such as cutting and painting,

7) the best working plan is the non-existent one; let the customer pull, and have a responsive organization. Unneeded planning is just a waste of time and resources,

8) no bosses are needed in connected processes. The boss's job is to set targets, support improvements, train, and bring in new business. 
After the lean game, which simulates the real assembly process, employees (and managers) are motivated and engaged, coming up with great insights and suggestions for what could be improved in their company. This is the time to take them seriously, and to improve operations together. In the case of leadership teams, they are prepared to move into the same direction, using the best industrial practices. Even better results are obtained by creating groups of approximately 15 employees and playing the game with all employees. It is much cheaper and more effective than playing positional wars - on one side leaders pushing the changes and on the other side everybody else pushing back. Why not journey and improve together, and have fun doing it? This game has served as a game changer in many practical cases and has proven that it is simple to play and it makes it easy to understand the results, which confirms its effectiveness.

In this chapter, we presented the lean game, which can be actually played in different workshops to get a better involvement of all the stakeholders (assembly and management workers) and to motivate them to co-operate. Since the game lasts only 20 minutes all together, it is difficult to analyse and to show the impact of different changing attributes of the production with the results of both, the push and the pull strategies. For this reason, we present in the next chapter the simulation models of both lean game strategies. We can use the Virtual factory with developed simulation models in the continuation of the workshop, once the participants become highly motivated, to go into deeper and further analysis of the production process over a longer production time, and to show the impact of different production attributes.

\section{SIMULATION MODELS OF LEAN GAMES}

Both examples of lean games need to be verified and should be tested with different scenarios [35-38]. For this reason, appropriate simulation models were developed for both cases of lean games.

The models have been developed in standard discrete event simulation tool Siemens Tecnomatix Plant Simulation. The simulation tool is user-friendly, object oriented, it provides effective graphical presentation of the production process through the simulation performing, and enables the coding of logical dependences through programming in SimTalk [39, 40].

The logical structure of the models was developed after studying and comparing the findings in the available literature [41-46] and previous research work [47, 48].

\subsection{Model of the push lean game}

The model of Game 1 (Fig. 3) is based on the logical scheme of the production process which is used for the interactive Game 1 (Fig. 1). The model covers an identical production process to the one in the interactive Game 1.

Special attention was focused on the modelling of intermediate storages and the strategy of moving the pieces over the production system [49, 50]. For each workplace, it is valid for the worker to perform the task and postpone the semi-finished product in an intermediate warehouse. Once the intermediate stock reaches $3 \mathrm{pcs}$, the transporter is called to transfer the pieces to the next workplace. There is only one transporter in the system, and he carries out transportations in the sequence in which they were called. Every workplace incorporates the decision about what percentage of the parts is acceptable and what percentage is not acceptable. The logical dependencies in the model are solved over 120 programming lines.

The results of the simulation performing with identical input data to the data used in the interactive Game 1 are discussed below. 


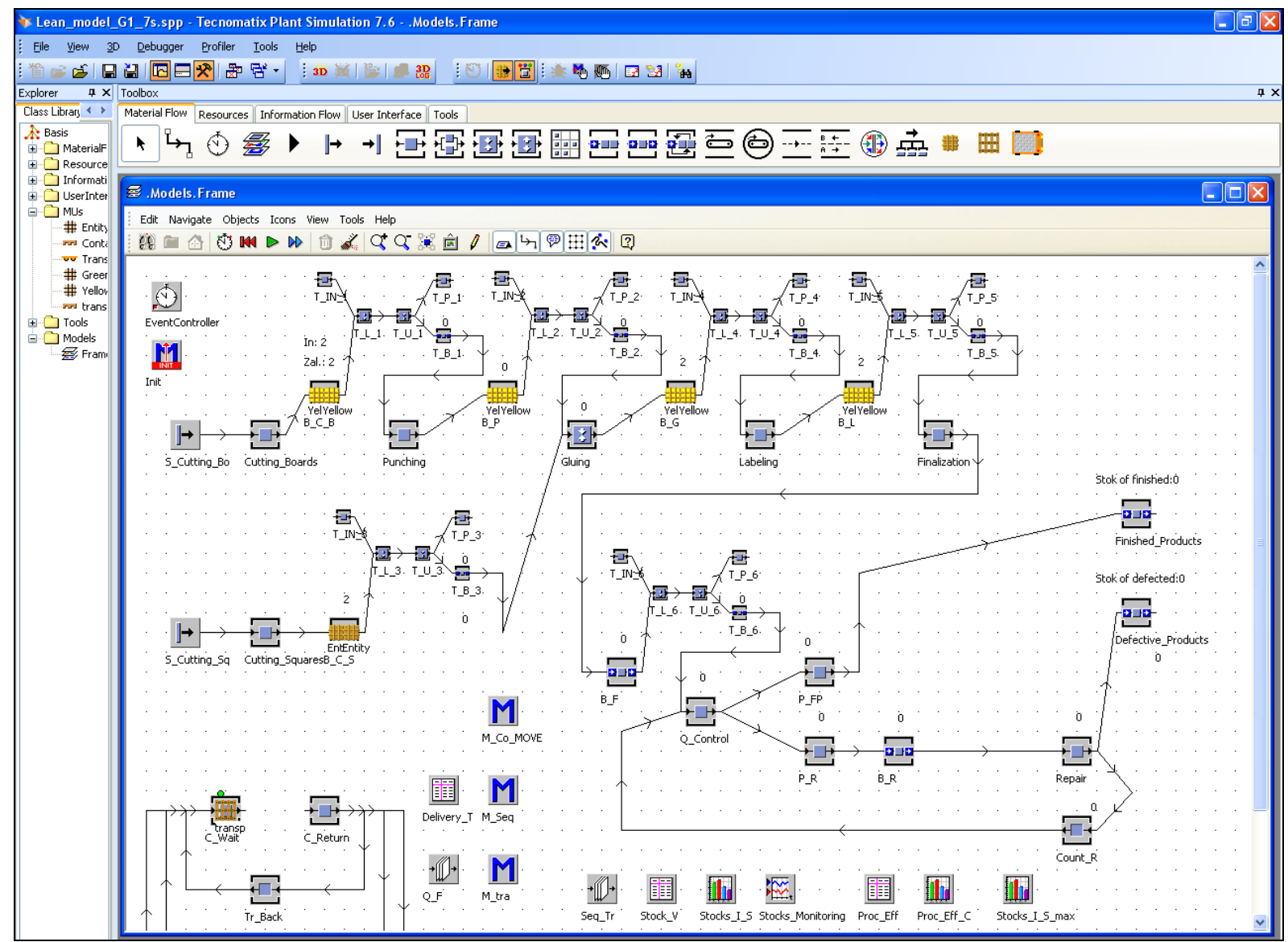

Figure 3: Simulation model of the production process in the Interactive Lean Game 1.

\subsection{Model of the pull lean game}

The model of Game 2 (Fig. 4) is based on the logical scheme of the production process which is used for the interactive Game 2 (Fig. 2). The model covers an identical production process to the one in the interactive Game 2.

In the model, a logical solution for the pull strategy is developed. Identical input data to the one in the game was tested in the model.

It is typical of this process that all storages for each different part have capacity 1 . The customer, on the basis of a strategy or plan, takes the finished products from the final storage (Fig. 2, IS5 and also Fig. 4, Y_5 and G_5), and so the capacity in the storage is reduced to 0 . At this moment, the requirement to produce the missing part is triggered at the station in front of the storage with 0 capacity. The logic of triggering the production of semi-finished parts is performed by the same principle at all other workplaces. Every workplace incorporates the decision that $99 \%$ of the pieces are acceptable. The logical dependencies in the model are solved over 830 programming lines.

The results of the simulation performing with an identical input data to the one used in the interactive Game 2 are discussed below.

\subsection{KPIs of the push and pull strategies from simulation results}

With both simulation models, test runs for the push and pull production strategies for the period of 600 seconds have been conducted. Furthermore, a comparison of the amount of the finished products has been made between the results of the simulation and the results from the interactive lean game (Table II). The result shows the adequacy of both simulation models of 
the lean games, and so the models are verified and deemed appropriate for simulating simulation runs for different production situations.

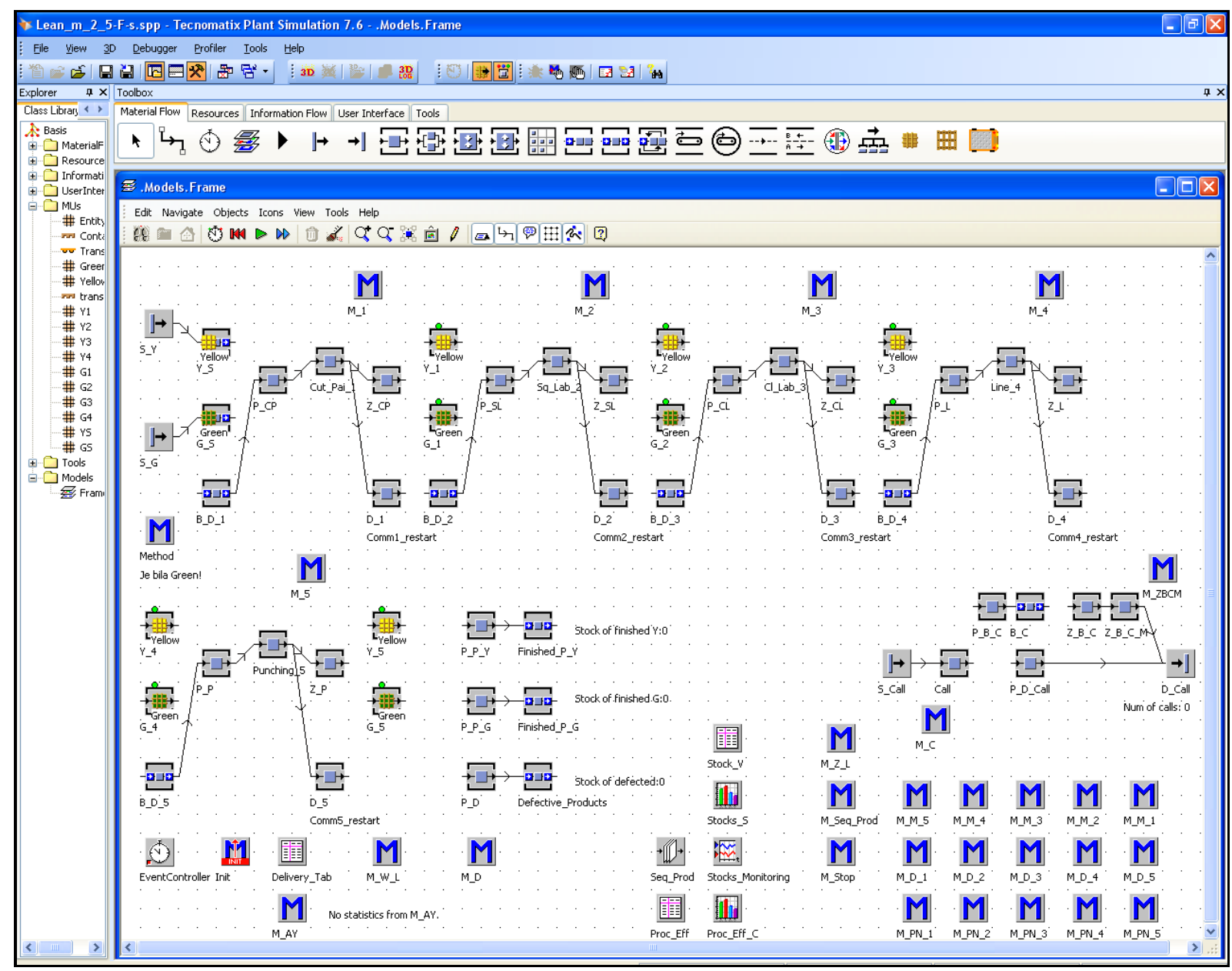

Figure 4: Simulation model of the production process in the Interactive Lean Game 2.

For both strategies (Lean Game 1 and 2), the acquired number of finished parts is equal when the results from the interactive game and from the simulation model are compared. The results prove the correctness of both simulation models, and this demonstrates that both models are applicable for the testing of interactive games, and may further be used to test production strategies with different parameters of the production processes.

Table II: Comparison of the finished parts for different production process variants.

\begin{tabular}{|l|c|c|}
\hline Production process variant & $\begin{array}{c}\text { Number of finished parts in } \\
\text { the period of 600 s }\end{array}$ & $\begin{array}{c}\text { Number of defected parts in } \\
\text { the period of 600 s }\end{array}$ \\
\hline Lean game 1 (push) & 1 & 1 \\
\hline Simulation model of Lean Game 1 & 1 (Yellow) & 1 (Yellow) \\
\hline Lean game 2 (pull) & 18 & 0 \\
\hline Simulation model of Lean Game 2 & 15 Yellow and 3 Green =18 & 0 \\
\hline
\end{tabular}

In the model of Game 1, we may also show the actual state of stocks in the intermediate storages (Fig. 5) and the efficiency of workplaces (Fig. 6). From the diagram, it is clear that with the push strategy the stocks in intermediate storages are accumulating. 


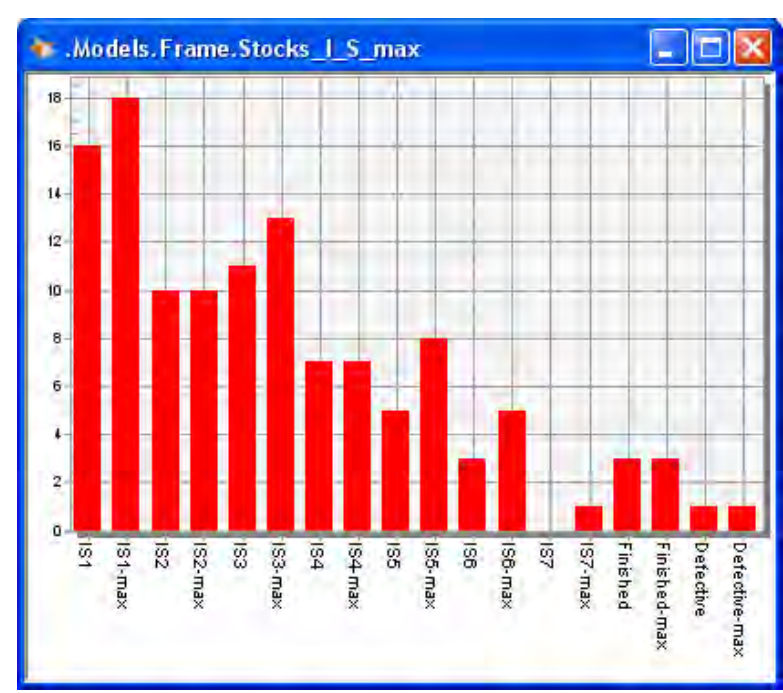

Figure 5: Stocks in intermediate storages after $600 \mathrm{~s}$ in the model of Lean Game 1.

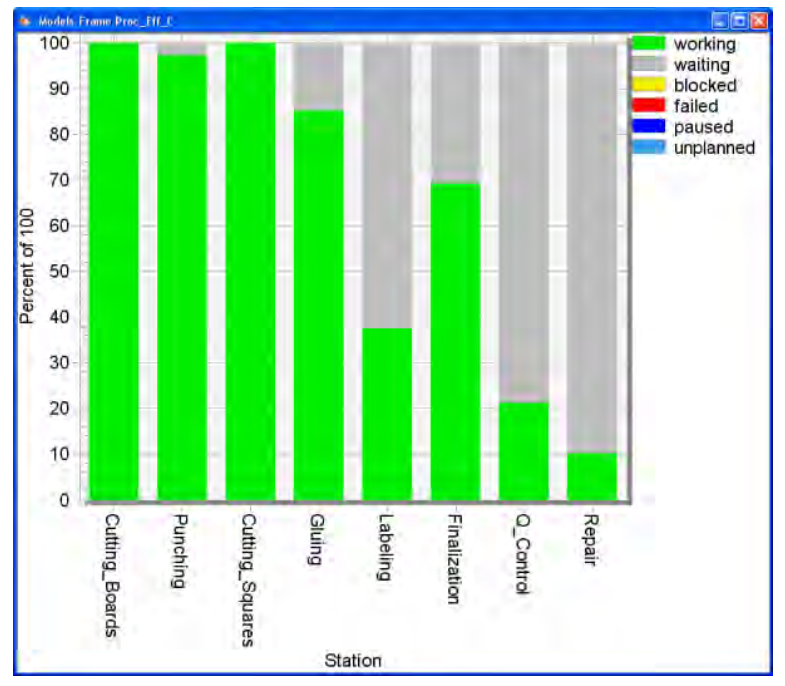

Figure 6: Efficiency of workplaces after $600 \mathrm{~s}$ in the model of Lean Game 1.

In the model of Game 2, we may also show the efficiency of workplaces (Fig. 7) which indicates a more uniform efficiency of workplaces as compared to the results from the model of Lean Game 1.

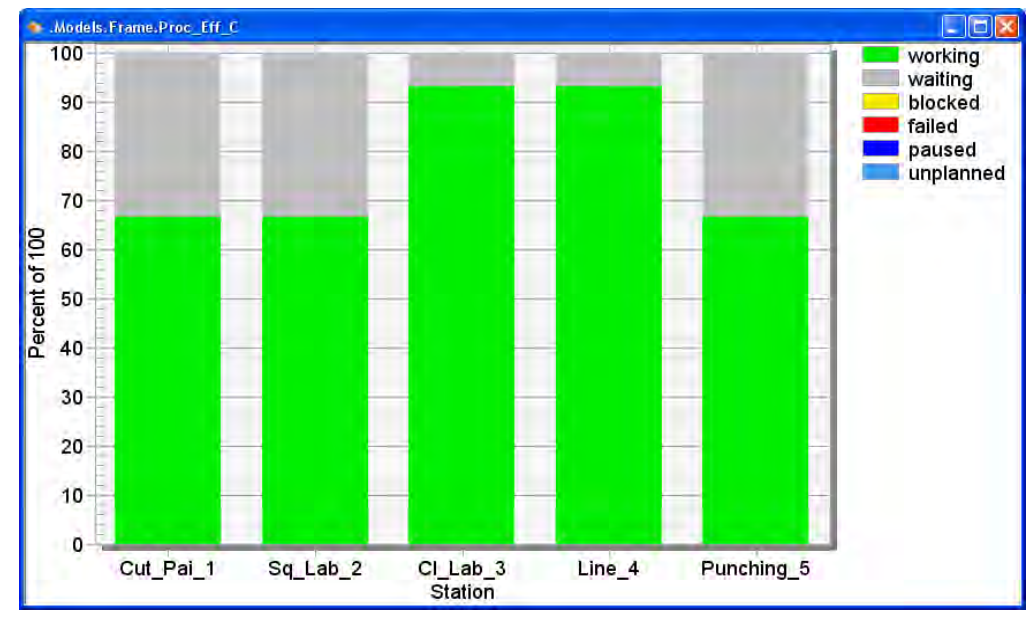

Figure 7: Efficiency of workplaces after $600 \mathrm{~s}$ in the model of Lean Game 2.

\section{DISCUSSION}

The proposed and in practice already proven and verified interactive lean game, which simulates the real assembly process, involves all employees (and managers) in the company. With the astonishing results which the game delivers and which each participant can see for themselves, the game can help us motivate and engage all stakeholders of a company, as well as achieve effective and quick improvements of the production process in each company, university course, or even in the government.

The interactive lean game can be adapted to each company's activities and can be carried out only for a short period of time or a smaller number of operations. It can help test several variants and analyse the outputs. Since the analysis of longer periods of the production process is very time-consuming, simulation models of the same game can help us further. It is important that we first play the physical lean game and then use the simulation models 
together with the workshop participants for further analysis of different production attributes and discussion of the results.

The developed simulation models have clearly demonstrated their usefulness. With their help, it is easy to observe the behaviour of the manufacturing process for any period of time and with different production parameters. In a longer observation time period, the influence of working shifts, breaks and random influencing factors (e.g. percentage of defected parts) on the number of produced units is shown. By changing the production parameters of working processes we can search for the optimal parameters for the operating of the production system.

In the case of the push working process, where transportation between workplaces is performed by a forklift, the simulation model enables an easy performing of various experiments. We can vary the number of transporters, or we can observe different periods of the working system operation, and we can observe the output of the process (Table III).

As we can see in the second lean game with the pull strategy, the customer demands are even tougher, as is the case in real life. The customer can even require 4 product codes, 2 yellow having holes in dark or bright areas, and the same for the green, without giving any order in advance, but just pulling products every 30 seconds or less from the final warehouse. This does not influence much the astonishingly excellent results of the game and the quantity produced.

Table III: Number of finished parts for different production process parameters from the model of Lean Game 1.

\begin{tabular}{|l|c|c|c|}
\hline & $\begin{array}{c}\text { Number of } \\
\text { finished parts in } \\
\text { the period of } 600 \mathbf{~ s}\end{array}$ & $\begin{array}{c}\text { Number of finished } \\
\text { parts in the period } \\
\text { of } \mathbf{2 8 . 8 0 0} \mathbf{~} \mathbf{8} \mathbf{~ h})\end{array}$ & $\begin{array}{c}\text { Number of defected } \\
\text { parts in the period of } \\
\mathbf{1 4 4 . 0 0 0} \mathbf{~}(\mathbf{5} \text { days x } \mathbf{~ h} \text { ) }\end{array}$ \\
\hline \multirow{2}{*}{1 transporter } & $\begin{array}{c}3 \text { finished } \\
1 \text { defected }\end{array}$ & $\begin{array}{c}341 \text { finished } \\
43 \text { defected }\end{array}$ & $\begin{array}{l}1722 \text { finished } \\
215 \text { defected }\end{array}$ \\
\hline 2 transporters & 6 finished & 551 finished & 2778 finished \\
& 1 defected & 69 defected & 347 defected \\
\hline 3 transporters & 6 finished & 551 finished & 2778 finished \\
& 1 defected & 69 defected & 347 defected \\
\hline
\end{tabular}

\section{CONCLUSION}

In the proposed interactive lean game we combine the physical and simulation approaches for an effective motivation of the participants, and for a deeper analysis of the production process. The game has been used in more than 50 practical cases in different real-case environments. The results illustrate the usefulness of this technique, mainly due to the active involvement of employees in the implementation of the interactive game. One of the essential advantages of our interactive game is that it does not consume energy and it is not necessary to build real production systems (test environment). The obtained results clearly show which type of production system is more suitable and in which direction it is necessary to develop the production system. It has been shown through the implementation of the interactive game in enterprises that such a method of optimizing the production is properly oriented and motivates participants to actively search for better solutions in the production system.

Upgrading the interactive games with simulation models demonstrated, firstly, their usefulness for the verification and validation of the lean game, and the fact that it is a useful model for future use. And secondly, it was shown that the models are a very useful tool for testing different scenarios with different input data, and the output data can be acquired in a very short time, even for long lasting production processes. So we can say that with the help 
of the simulation we can acquire the response of the model to the input data and set parameters very quickly. This possibility reduces significantly the time usually spent for the optimization of production systems.

In this paper, we have explored the nature of the push and pull systems, and have proposed the lean game, which shows the effect of both strategies very effectively in only 20 minutes, which highly motivates all stakeholders for further optimization steps of the production process. Such a scientific approach of using the lean game together with the simulation of the production processes can contribute to the reduction of discussions of the benefits of the pull vs. the push systems, and deliver an advanced understanding and implementation of a work in process (WIP) control as a fundamental determinant of the manufacturing supply chain performance.

\section{REFERENCES}

[1] Automatica (2014). Automatica - Accompanying Program: Smart factory, $6^{\text {th }}$ International Trade Fair for Automation and Mechatronics, Munich

[2] Hopp, W. J.; Spearman, M. L. (2001). Factory Physics: Foundations of Manufacturing Management, McGraw-Hill, New York

[3] Huang, C.-C.; Kusiak, A. (1996). Overview of Kanban systems, International Journal of Computer Integrated Manufacturing, Vol. 9, No. 3, 169-189, doi:10.1080/095119296131643

[4] Uzsoy, R.; Martin-Vega, L. A. (1990). Modeling Kanban based and demand-pull systems: a survey and critique, Manufacturing Review, Vol. 3, No. 3, 155-160

[5] Bandyopadhyay, J. K.; Jayaram, M. J. (1995). Implementing Just-In-Time production and procurement strategies, International Journal of Management, Vol. 12, No. 1, 83-90

[6] Kootanaee, A. J.; Babu, K. N.; Talari, H. F. (2013). Just-in-Time manufacturing system: from introduction to implement, International Journal of Economics, Business and Finance, Vol. 1, No. 2, 7-25

[7] Buchmeister, B.; Friscic, D.; Lalic, B.; Palcic, I. (2012). Analysis of a three-stage supply chain with level constraints, International Journal of Simulation Modelling, Vol. 11, No. 4, 196-210, doi:10.2507/IJSIMM11(4)3.212

[8] Lyonnet, B.; Pralus, M.; Pillet, M. (2010). A Push-Pull manufacturing strategy: analytical model in the screw cutting sector, Proceedings of the World Congress on Engineering 2010, 2306-2312 (Vol. III), London

[9] Belekoukias, I.; Garza-Reyes, J. A.; Kumar, V. (2014). The impact of lean methods and tools on the operational performance of manufacturing organisations, International Journal of Production Research, Vol. 52, No. 18, 5346-5366, doi:10.1080/00207543.2014.903348

[10] Powell, D.; Riezebos, J.; Strandhagen, J. O. (2013). Lean production and ERP systems in smalland medium-sized enterprises: ERP support for pull production, International Journal of Production Research, Vol. 51, No. 2, 395-409, doi:10.1080/00207543.2011.645954

[11] Dordevic, M. S.; Zrnic, N. D.; Milicevic, M. R.; Miskovic, V. V. (2013). Information and material flow modeling in system of parts regeneration in multi-level supply system, Technical Gazette, Vol. 20, No. 5, 861-869

[12] Bozickovic, R.; Radosevic, M.; Cosic, I.; Sokovic, M.; Rikalovic, A. (2012). Integration of simulation and lean tools in effective production systems, Strojniski vestnik - Journal of Mechanical Engineering, Vol. 58, No. 11, 642-652, doi:10.5545/sv-jme.2012.387

[13] Berlec, T.; Kusar, J.; Zerovnik, J.; Starbek, M. (2014). Optimization of a product batch quantity, Strojniski vestnik - Journal of Mechanical Engineering, Vol. 60, No. 1, 35-42, doi:10.5545/svjme.2013.1009

[14] Ohno, T. (1988). Toyota Production Systems: Beyond Large-Scale Production, Productivity Press, Portland

[15] Womack, J.; Jones, D. (2003). Lean Thinking: Banish Waste and Create Wealth in Your Corporation, Free Press, New York 
[16] Drew, J.; Mc Callum, B.; Rogenhoffer, S. (2004). Journey to Lean: Making Operational Change Stick, Palgrave Macmillan, New York

[17] Hicks, B. J. (2007). Lean information management: understanding and eliminating waste, International Journal of Information Management, Vol. 27, No. 4, 233-249, doi:10.1016/j.ijinfomgt.2006.12.001

[18] Sutee, U.; Yarlagadda, P. K. D. V. (2013). Simulation-based comparison of pull-push systems in motorcycle assembly line, Applied Mechanics and Materials, Vols. 241-244, 1507-1513, doi:10.4028/www.scientific.net/AMM.241-244.1507

[19] Pound, E. S.; Spearman, M. L. (2007). The Great Push vs. Pull Diversion, Industry Week, from http://www.industryweek.com/companies-amp-executives/great-push-vs-pull-diversion, accessed on 14-04-2014

[20] Chiadamrong, N.; Techalert, T.; Pichalai, A. (2007). Decision support tool for evaluating push and pull strategies in the flow shop with a bottleneck resource, Industrial Engineering \& Management Systems, Vol. 6, No. 1, 83-93

[21] Brem, A.; Voigt, K.-I. (2009). Integration of market pull and technology push in the corporate front end and innovation management - insights from the German software industry, Technovation, Vol. 29, No. 5, 351-367, doi:10.1016/j.technovation.2008.06.003

[22] Maher, J.; Denison, R. (2013). Gaining Control: Exploring Push v Pull Manufacturing, from http://www.plantservices.com/assets/Media/1407/gaining-control-push-pull-manufacturing.pdf, accessed on 15-04-2014

[23] Helleno, A. L.; Simon, A. T.; Papa, M. C. O.; Ceglio, W. E.; Rossa Neto, A. S.; Mourad, R. B. A. (2013). Integration university-industry: laboratory model for learning lean manufacturing concepts in the academic and industrial environments, International Journal of Engineering Education, Vol. 29, No. 6, 1387-1399

[24] Choomlucksana, J.; Doolen, T. L. (2013). The impact of collaborative and simulation sessions on learning lean principles and methods: a multi-institutional study, International Journal of Engineering Education, Vol. 29, No. 6, 1514-1526

[25] Senk, I.; Ostojic, G.; Jovanovic, V.; Tarjan, L.; Stankovski, S. (2014). Experiences in developing labs for a supervisory control and data acquisition course for undergraduate Mechatronics education, Computer Applications in Engineering Education, In Press, doi:10.1002/cae.21578

[26] Stankovski, S.; Lazarevic, M.; Ostojic, G.; Cosic, I.; Puric, R. (2009). RFID technology in product/part tracking during the whole life cycle, Assembly Automation, Vol. 29, No. 4, 364-370, doi:10.1108/01445150910987781

[27] Zavbi, R.; Benedicic, J.; Duhovnik, J. (2010). Use of mixed academic-industrial teams for new product development: delivering educational and industrial value, International Journal of Engineering Education, Vol. 26, No. 1, 178-194

[28] Powell, D.; Alfnes, E.; Strandhagen, J. O.; Dreyer, H. (2013). The concurrent application of lean production and ERP: towards an ERP-based lean implementation process, Computers in Industry, Vol. 64, No. 3, 324-335, doi:10.1016/j.compind.2012.12.002

[29] Buchmeister, B.; Friscic, D.; Palcic, I. (2013). Impact of demand changes and supply chain's level constraints on bullwhip effect, Advances in Production Engineering \& Management, Vol. 8, No. 4, 199-208, doi:10.14743/apem2013.4.167

[30] Dal Forno, A. J.; Pereira, F. A.; Forcellini, F. A.; Kipper, L. M. (2014). Value Stream Mapping: a study about the problems and challenges found in the literature from the past 15 years about application of Lean tools, International Journal of Advanced Manufacturing Technology, Vol. 72, No. 5-8, 779-790, doi:10.1007/s00170-014-5712-z

[31] Stefanic, N.; Gjeldim, N.; Mikac, T. (2010). Lean concept application in production business, Technical Gazette, Vol. 17, No. 3, 353-356

[32] Dues, C. M.; Tan, K. H.; Lim, M. (2013). Green as the new Lean: how to use Lean practices as a catalyst to greening your supply chain, Journal of Cleaner Production, Vol. 40, 93-100, doi:10.1016/j.jclepro.2011.12.023

[33] Demaine, E. D.; Ghodsi, M.; Hajiaghayi, M. T.; Sayedi-Roshkhar, A. S.; Zadimoghaddam, M. (2013). Scheduling to minimize gaps and power consumption, Journal of Scheduling, Vol. 16, No. 2, 151-160, doi:10.1007/s10951-012-0309-6 
[34] Jovanovic, V.; Stevanov, B.; Seslija, D.; Dudic, S.; Tesic, Z. (2014). Energy efficiency optimization of air supply system in a water bottle manufacturing system, Journal of Cleaner Production, In Press, doi:10.1016/j.jclepro.2014.03.021

[35] Ku, H.; Fulcher, R. (2012). Using computer software packages to enhance the teaching in Engineering Management Science: part 3 - simulation, Computer Applications in Engineering Education, Vol. 20, No. 3, 547-552, doi:10.1002/cae.20423

[36] Mavrikios, D.; Papakostas, N.; Mourtzis, D.; Chryssolouris, G. (2013). On industrial learning and training for the factories of the future: a conceptual, cognitive and technology framework, Journal of Intelligent Manufacturing, Vol. 24, No. 3, 473-485, doi:10.1007/s10845-011-0590-9

[37] Perdukova, D.; Fedor, P. (2013). Virtual laboratory for the study of technological process automation, International Journal of Engineering Education, Vol. 29, No. 1, 230-238

[38] Cagiltay, N.; Ozalp-Yaman, S. (2013). How can we get benefits of computer-based testing in engineering education?, Computer Applications in Engineering Education, Vol. 21, No. 2, $287-$ 293, doi: $10.1002 / \mathrm{cae} .20470$

[39] Siemens. Tecnomatix Plant Simulation, from http://www.plm.automation.siemens.com/en_us/ products/tecnomatix/manufacturing-simulation/material-flow/plant-simulation.shtml, accessed on 07-04-2014

[40] Bangsow, S. (2010). Manufacturing simulation with Plant Simulation and Simtalk: Usage and Programming with Examples and Solutions, Springer-Verlag, Berlin

[41] Savarese, A. B. (2011). Manufacturing Engineering, Nova Science Publishers, Inc., New York

[42] Stahl, B.; Cerinsek, G.; Colombo, F.; Taisch, M. (2012). Development of competence for sustainable manufacturing by using serious games, Transactions of FAMENA, Vol. 36, No. 4, 6372

[43] Mandic, V.; Eric, D.; Adamovic, D.; Janjic, M.; Jurkovic, Z.; Babic, Z.; Cosic, P. (2012). Concurrent engineering based on virtual manufacturing, Technical Gazette, Vol. 19, No. 4, 885892

[44] Robinson, S.; Radnor, Z. J.; Burgess, N.; Worthington, C. (2012). SimLean: utilising simulation in the implementation of lean in healthcare, European Journal of Operational Research, Vol. 219, No. 1, 188-197, doi:10.1016/j.ejor.2011.12.029

[45] Cerinsek, G.; Petersen, S. A.; Heikura, T. (2013). Contextually enriched competence model in the field of sustainable manufacturing for simulation style technology enhanced learning environments, Journal of Intelligent Manufacturing, Vol. 24, No. 3, 441-455, doi:10.1007/ s10845-011-0554-0

[46] Perme, T. (2011). Modelling and discrete simulation for the sustainable management of production and logistics issues, Transactions of FAMENA, Vol. 35, No. 1, 83-90

[47] Debevec, M. (2010). Modeling of Tools Handling in Manufacturing for Digital Environment, Ph.D. Dissertation, University of Ljubljana, Faculty of Mechanical Engineering, Ljubljana

[48] Debevec, M.; Simic, M.; Herakovic, N. (2014). Virtual factory as an advanced approach for production process optimization, International Journal of Simulation Modelling, Vol. 13, No. 1, 66-78, doi:10.2507/IJSIMM13(1)6.260

[49] Padhi, S. S.; Wagner, S. M.; Niranjan, T. T.; Aggarwal, V. (2013). A simulation-based methodology to analyse production line disruptions, International Journal of Production Research, Vol. 51, No. 6, 1885-1897, doi:10.1080/00207543.2012.720389

[50] Kim, C.; Dudin, A.; Dudina, O.; Dudin, S. (2014). Tandem queueing system with infinite and finite intermediate buffers and generalized phase-type service time distribution, European Journal of Operational Research, Vol. 235, No. 1, 170-179, doi:10.1016/j.ejor.2013.12.012 